08

\title{
Модель ограничения скорости роста углеродных нанотрубок \\ на тонкопленочных катализаторах
}

\author{
(c) С.В. Булярский ${ }^{1}$, А.В. Лакалин ${ }^{1}$, А.А. Павлов ${ }^{2}$, А.А. Дудин ${ }^{2}$,
} Е.П. Кицюк ${ }^{2}$, Е.М. Еганова ${ }^{2}$, А.П. Сиротина ${ }^{2}$, А.А. Шаманаев ${ }^{2}$

${ }^{1}$ Ульяновский государственный университет, Ульяновск

${ }^{2}$ Институт нанотехнологий микроэлектроники РАН, Москва

E-mail: bulyar2954@mail.ru

Поступило в Редакцию 12 мая 2016 г.

Экспериментально и теоретически показано, что замедление скорости роста углеродных нанотрубок на тонкопленочных катализаторах может быть обусловлено формированием интерметаллических соединений, которые затрудняют поступление углерода из объема. В частности, при росте углеродных нанотрубок из системы тонких пленок Тi и $\mathrm{Ni}$ на поверхности капли катализатора формируется слой карбида титана. Рассчитана кинетика роста нанотрубки в этом случае и определены кинетические коэффициенты, которые определяют скорость роста.

DOI: $10.21883 /$ PJTF.2017.08.44528.16328

При определенных условиях рост углеродных нанотрубок (УНТ) замедляется вплоть до полной остановки [1-3]. Это объясняется тем, что рост массива УНТ затрудняет проникновение углерода из газовой фазы реактора к катализатору, расположенному на подложке, из-за ограничения диффузионного потока [1,2]. Если катализатор расположен на кремнии, то прекращение роста может быть связано с образованием силицидов [3]. Однако последний механизм не может объяснить замед- 


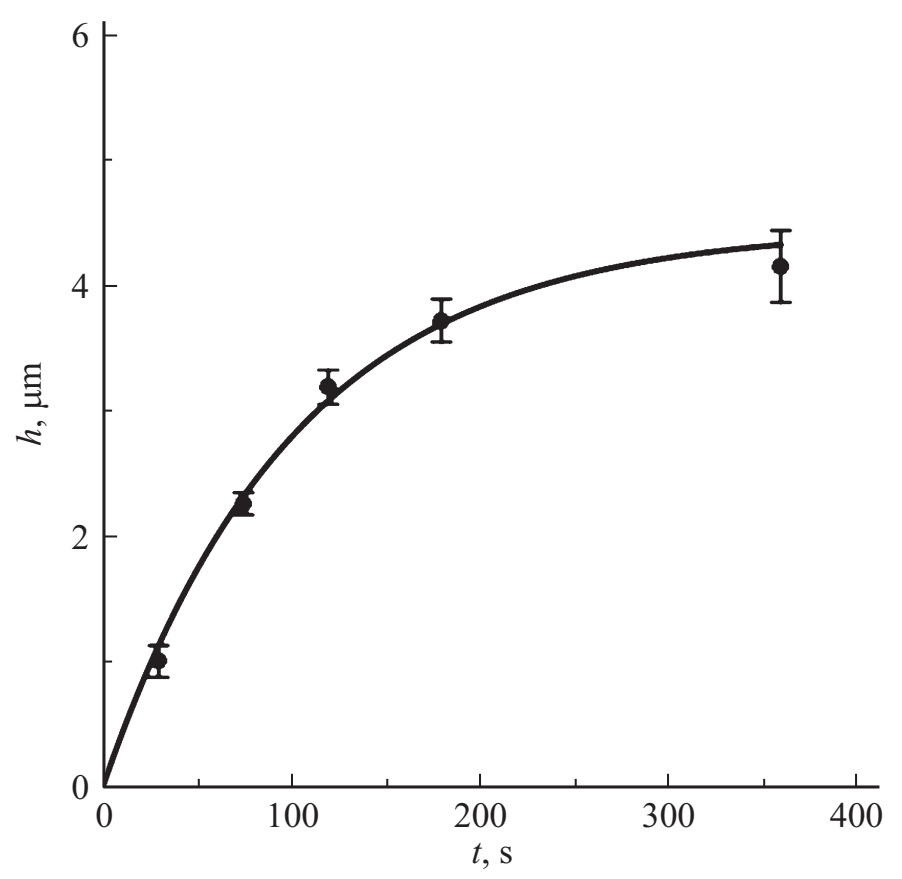

Рис. 1. Высота массива углеродных нанотрубок в зависимости от времени синтеза: точки - экспериментальные данные, сплошная линия - расчет.

ление и остановку роста в случае, когда между катализатором и кремнием имеется буферный слой, препятствующий образованию силицидов. Диффузия углерода к катализатору происходит беспрепятственно, если нанотрубки растут в виде пучков, что достигается разрежением массива. Тем не менее и в этих случаях рост массива прекращается.

В данной работе исследуются причины замедления и остановки роста нанотрубок на тонкопленочных катализаторах и показывается, что это может быть связано с образованием соединений на поверхности катализатора, которые препятствуют проникновению в него углерода.

УНТ были синтезированы методом плазмостимулированного химико-парофазного осаждения (ПСХПО) в установке на базе Oxford Plasmalab System 100. В качестве катализатора были нанесены тонкие

Письма в ЖТФ, 2017, том 43, вып. 8 


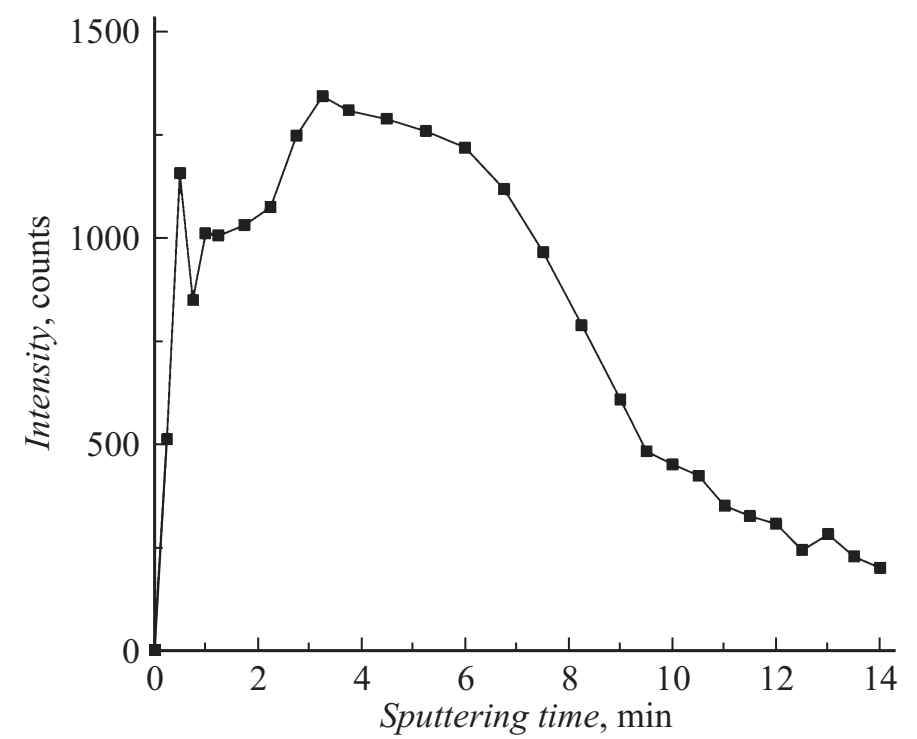

Рис. 2. Зависимость интенсивности оже-пика углерода, связанного в карбиде титана, от времени ионного травления.

пленки титана $(10-15 \mathrm{~nm})$ и никеля $(2-4 \mathrm{~nm})$. Пленка титана была сплошной, а никель формировал островки высотой не более $1-5 \mathrm{~nm}$. Подслой титана формировал буферный слой, а никель служил катализатором. Рост происходил при температурах от 550 до $650^{\circ} \mathrm{C}$. Формирование катализаторов и массива УНТ контролировалось растровым электронным микроскопом HeliosNanoLab 650 фирмы FEI, атомно-силовым микроскопом (ACM) Dimension Icon фирмы Brucker и оже-электронным спектрометром Jamp 9510F компании JEOL. Исследования показали, что рост массива со временем останавливается и в дальнейшем не зависит от времени нахождения образца в реакторе. В результате многократных опытов определена кинетика изменения высоты массива в доверительном интервале, найденном путем статистического усреднения (точки на рис. 1). Исследования с помощью АСМ показали, что на поверхности капли катализатора наблюдаются неоднородности с характерными размерами, превышающими погрешность прибора. Оже-

Письма в ЖТФ, 2017, том 43, вып. 8 
анализ показал, что кроме углерода, никеля и титана имеется фаза карбида титана (рис. 2). Концентрация карбида титана убывает по мере травления ионами аргона в камере анализа оже-электронного спектрометра. Это позволяет предположить, что карбид титана расположен на поверхности катализатора. Подобный результат также наблюдался в работе [4].

Проведенные эксперименты позволяют предложить следующий механизм гетерогенного формирования катализатора. Островковая пленка никеля в процессе выхода на режим синтеза плавится, частично растворяя титан. УГлерод, проникая в катализатор из реактора, формирует карбиды никеля и титана. Карбид титана обладает высокой температурой плавления и является очень стабильным соединением, о чем свидетельствуют большая теплота образования $(-183 \mathrm{~kJ} / \mathrm{K})$ и большое изменение свободной энергии при образовании из элементов $(-236 \mathrm{~kJ} /(\mathrm{K} \cdot \mathrm{mol}))[5]$. Образование таких соединений идет активно и до полного истощения одного из компонентов. В отличие от титана, эти величины для никеля малы, он легко разлагается на фронте формирования нанотрубки, поставляя углерод для ее роста. Так как углерод поступает в катализатор с поверхности, то именно на его поверхности формируется карбид титана, который первоначально образует островки, а в конце концов может создать на поверхности катализатора корку, которая будет препятствовать дальнейшему поступлению углерода в каплю катализатора. В этом случае концентрация углерода снижается, рост замедляется и при полном покрытии поверхности коркой останавливается.

Было выполнено математическое моделирование данных процессов, учитывающее формирование карбидов, распад карбида никеля и рост нанотрубки. Оно опирается на систему кинетических уравнений относительно трех неизвестных величин $\left(N_{\mathrm{C}}(t)-\right.$ количество атомов углерода, $N_{\mathrm{Ti}}(t)$ - титана, $N_{\mathrm{Ni}}(t)-$ никеля):

$$
\left\{\begin{array}{l}
\frac{d N_{\mathrm{C}}(t)}{d t}=-k_{\mathrm{Ni}_{3} \mathrm{C}} N_{\mathrm{Ni}}(t) N_{\mathrm{C}}(t)-k_{\mathrm{TiC}} N_{\mathrm{Ti}}(t) N_{\mathrm{C}}(t)+J_{\mathrm{C}} S_{0}\left(1-\alpha\left(N_{\mathrm{Ti}}^{0}-N_{\mathrm{Ti}}(t)\right)\right), \\
\frac{d N_{\mathrm{Ti}}(t)}{d t}=-k_{\mathrm{TiC}} N_{\mathrm{Ti}}(t) N_{\mathrm{C}}(t), \\
\frac{d N_{\mathrm{Ni}}(t)}{d t}=-k_{\mathrm{Ni}_{3} \mathrm{C}} N_{\mathrm{Ni}}(t) N_{\mathrm{C}}(t)+e_{\mathrm{Ni}_{3} \mathrm{C}}\left(N_{\mathrm{Ni}}^{0}-N_{\mathrm{Ni}}(t)\right),
\end{array}\right.
$$

где $N_{\mathrm{TiC}}-$ количество молекул карбида титана в твердой фазе; $N_{\mathrm{Ni}_{3} \mathrm{C}}-$ количество молекул карбида никеля; $N_{\mathrm{CNT}}-$ количество 
атомов углерода в УНТ; $k_{\mathrm{TiC}}-$ коэффициент образования молекул карбида титана; $k_{\mathrm{Ni}_{3} \mathrm{C}}-$ коэффициент образования молекул карбида никеля; $e_{\mathrm{Ni}_{3} \mathrm{C}}-$ коэффициент распада молекулы карбида никеля; $J_{\mathrm{C}}-$ поток атомов углерода из газа в расплав; $S=S_{0}\left(1-\alpha\left(N_{\mathrm{Ti}}^{0}-N_{\mathrm{Ti}}(t)\right)\right)-$ площадь поверхности жидкой фазы в расплаве, $\alpha-$ коэффициент пропорциональности между количеством атомов карбида титана в твердой фазе и площадью перекрываемой им поверхности жидкой фазы. При записи системы (1) использовались законы сохранения количества атомов никеля и титана: $N_{\mathrm{Ni}_{3} \mathrm{C}}(t)+N_{\mathrm{Ni}}(t)=N_{\mathrm{Ni}}^{0}=$ Const и $N_{\mathrm{TiC}}(t)+N_{\mathrm{Ti}}(t)=N_{\mathrm{Ti}}^{0}=$ Const.

Численно решив систему (2), находим $N_{\mathrm{C}}(t), N_{\mathrm{Ti}}(t), N_{\mathrm{Ni}}(t)$, а затем $N_{\mathrm{Ni}_{3} \mathrm{C}}(t), N_{\mathrm{TiC}}(t), S(t)$, производную $\frac{d N_{\mathrm{CNT}}(t)}{d t}$, которая характеризует скорость роста:

$$
\left\{\begin{array}{l}
N_{\mathrm{TiC}}(t)=N_{\mathrm{Ti}}^{0}-N_{\mathrm{Ti}}(t), \\
N_{\mathrm{Ni}_{3} \mathrm{C}}(t)=N_{\mathrm{Ni}}^{0}-N_{\mathrm{Ni}}(t), \\
\frac{d N_{\mathrm{CNT}}(t)}{d t}=e_{\mathrm{Ni}_{3} \mathrm{C}} N_{\mathrm{Ni}_{3} \mathrm{C}}(t)=e_{\mathrm{Ni}_{3} \mathrm{C}}\left(N_{\mathrm{Ni}}^{0}-N_{\mathrm{Ni}}(t)\right), \\
S(t)=S_{0}\left(1-\alpha\left(N_{\mathrm{Ti}}^{0}-N_{\mathrm{Ti}}(t)\right)\right) .
\end{array}\right.
$$

Пусть $V$ - скорость роста УНТ, $h$ - высота УНТ соответственно, $h(t)=\int_{0}^{t} V\left(t^{\prime}\right) d t^{\prime}$. Скорость роста УНТ пропорциональна подводимому потоку атомов углерода, т. е. $V(t) \propto \frac{d N_{\mathrm{CNT}}(t)}{d t}$. Тогда

$$
\begin{aligned}
h(t) & =\int_{0}^{t} V\left(t^{\prime}\right) d t^{\prime} \propto \int_{0}^{t} \frac{d N_{\mathrm{CNT}}\left(t^{\prime}\right)}{d t} d t=\int_{0}^{t} e_{\mathrm{Ni}_{3} \mathrm{C}} N_{\mathrm{Ni}_{3} \mathrm{C}}\left(t^{\prime}\right) d t^{\prime} \\
& =\int_{0}^{t} e_{\mathrm{Ni}_{3} \mathrm{C}}\left(N_{\mathrm{Ni}}^{0}-N_{\mathrm{Ni}}\left(t^{\prime}\right)\right) d t^{\prime} .
\end{aligned}
$$

Таким образом, решив систему (1) и найдя зависимость $N_{\mathrm{Ni}}(t)$, можно получить оценку зависимости высоты массива $h(t)$ от времени. На рис. 1 сплошной линией показан расчет кинетики изменения высоты массива, который хорошо описывает эксперимент.

Письма в ЖТФ, 2017, том 43, вып. 8 
В качестве подгоночных параметров выступали кинетические коэффициенты образования карбида титана и никеля $\left(k_{\mathrm{TiC}}, k_{\mathrm{Ni}_{3} \mathrm{C}}\right)$. Величины этих коэффициентов связаны с диффузией углерода в капле катализатора и могут оцениваться по формулам [3]

$$
k_{\mathrm{TiC}}=4 \pi D_{\mathrm{CTi}} a \quad k_{\mathrm{N}_{3} \mathrm{C}}=4 \pi D_{\mathrm{CNi}} a,
$$

где $D_{\mathrm{CTi}}, D_{\mathrm{CNi}}$ - коэффициенты взаимной диффузии углерода с титаном и углерода с никелем в капле расплавленного катализатора, $a$ характерное расстояние между атомами в расплаве. При расчете важно не абсолютное значение этих коэффициентов, а их отношение, которое определяется отношением коэффициентов диффузии. Отношение коэффициентов диффузии $D_{\mathrm{CNi}} / D_{\mathrm{CNTi}}$, удовлетворяющее эксперименту, равно 7.5. Это качественно согласуется с расчетами коэффициентов взаимной диффузии по формулам Даркина с использованием численных коэффициентов работы [5].

Таким образом, в работе экспериментально и теоретически показано, что формование катализатора продолжается после начала роста углеродных нанотрубок. Возникает новая твердая фаза, состоящая из карбида титана, разрастание которой по поверхности создает препятствие для проникновения углерода в катализатор, что приводит к падению скорости роста нанотрубок. Рассмотренная система не является единственной. В нашей предыдущей работе [6] показано, что в системе $\mathrm{Co}-\mathrm{Zr}-\mathrm{N}-\mathrm{O}$ образовалось интерметаллическое соединение и рост массива также останавливался спустя некоторое время от начала процесса. Однако при этом высота массива была иной и составляла $12 \mu \mathrm{m}$. Проведенные эксперименты и расчеты позволяют с новой точки зрения анализировать процессы роста углеродных нанотрубок.

При поддержке Министерства образования и науки РФ в рамках государственной поддержки научных исследований.

\section{Список литературы}

[1] Louchev O.A., Laude T., Sato Y., Kanda H. // J. Chem. Phys. 2003. V. 118. P. 7622-7634.

[2] Burmaka G.P., Denysenko I.B., Azarenkov N.A. // Probl. Atomic Sci. Technol. 2015. N 1. P. $184-186$. 
[3] Булярский C.B. Углеродные нанотрубки: технология, управление свойствами, применение. Ульяновск: Стрежень, 2011. С. 484.

[4] Guo C., Qian Y., Han P. // J. Nanomaterials. 2011. ID 987530. P. 5.

[5] Ситлз К. Металлы. М.: Металлургия, 1980. С. 446.

[6] Gromov D.G., Bulyarskii S.V., Pavlov A.A et al. // Diamond Relat. Mater. 2016. V. 64. P. $97-102$.

Письма в ЖТФ, 2017, том 43, вып. 8 